\title{
Meaning, Authority, Rationality and Care as MARCs of sustainable organisations
}

\author{
Alf Westelius, Ann-Sofie Westelius and Tomas Brytting
}

\section{Linköping University Post Print}

\section{Tweet}

N.B.: When citing this work, cite the original article.

Original Publication:

Alf Westelius, Ann-Sofie Westelius and Tomas Brytting, Meaning, Authority, Rationality and Care as MARCs of sustainable organisations, 2013, Cross Cultural Management, (20), 2.

Copyright: Emerald

http://www.emeraldinsight.com/

Postprint available at: Linköping University Electronic Press

http://urn.kb.se/resolve?urn=urn:nbn:se:liu:diva-87382 


\title{
Meaning, Authority, Rationality and Care as MARCs of sustainable and human-centred organisations
}

\author{
Alf Westelius \\ Department of Management and Engineering Linköping University, Linköping, Sweden
}

Ann-Sofie Westelius

Moral Space HB, Saltsjöbaden, Sweden

Tomas Brytting

Institute for Organizational and Worklife Ethics Ersta Sköndal University College, Stockholm, Sweden

\begin{abstract}
The purpose of the article is to present MARC, a model for assessing - and improving - the health of organisations from a humanistic point of view. The model has been developed in an organisational development clinical research tradition. The validity of the model rests on logical reasoning grounded in organisational and salutogenic research, and on it appearing useful to our clients and members in organisations where we have employed $i$. When using the MARC model to structure analyses and facilitate discussions in organisations that have sought our aid, the model has helped reveal major sources of imbalance between its four aspects: Meaning, Authority, Rationality and Care. A major survey revealed no statistically significant differences between men and women. This indicates that the MARC concepts are general rather than gender-specific. The results also contradicted the often stated notion that men emphasise "hard" aspects ( $A$ and $R$ ) while women emphasise "soft" ones ( $M$ and $C$ ). We demonstrate that support for the importance of each of the four aspects as perspectives in analysing and understanding organisations can be found in the organisational research literature. Our contribution is to argue the case that they represent four important human needs that need to be attended to in balance in an organisation if cooperation between the individuals in the organisation is to be sustainable from a human-centred perspective. MARC is designed to help visualise and focus this balance.
\end{abstract}

Keywords: sustainability, work/life balance, business ethics, organisational culture, values 


\section{Introduction}

In this article, we present MARC, a model for assessing - and improving - the health of organisations from a humanistic point of view. We relate this model to other multi-perspective models and theories in organisation theory and health, explore the interplay of the parts of the model, study its opposite, and discuss its implications. The purpose of the model is to serve as a compact, illustrative aid for keeping human-centred values in focus when analysing, discussing and addressing organisational imbalances. MARC is a part of the quest for sustainability - currently a main theme in organisations especially regarding prerequisites for facilitating trustful and productive partnerships despite differing cultural backgrounds and gender differences.

The article is structured as follows. Firstly, we review the concept sustainability from an organisational and human-centred perspective. Next, we study alternative theoretical perspectives on organisations. Thereafter, we discuss the relationships between values and sustainability, followed by an examination of connections between individual and organisational sustainability. We then focus on the MARC model, the balancing of potentially conflicting values, discuss the dynamism between the parts of the model, and use the model to explore threats to sustainability and how to cope with them. Finally, we provide experiences from our use of the model and give examples from a number of organisations. The article ends with conclusions and suggestions for future research.

\section{Sustainability and organisations}

What is then sustainability according to our view, and why is it desirable? Some take a very large scope, and view sustainability in terms of the organisation's contributions (or threats) to ecological, social and economic stability in a global and multi-generation perspective (Lozano 2008). According to the market failure perspective, organisations are the result of time- and space-specific obstacles for the appearance of perfect spot-market solutions (Coase 1937). High transaction-costs caused by combinations of: bounded rationality; opportunism; uncertainty and small numbers, makes structured incomplete contracts - i.e. "hierarchies" or "organisations" - more efficient than detailed spot-market exchanges (Williamson 1975). Others view sustainable organisations as a question of whether the organisations can keep alive and perhaps even grow over time. Focus could then rest, for example, on the organisation's ability to innovate and adapt to changing conditions (Kjellberg \& Werneman 2000). However, even in that tradition it has long been recognised that continued existence is not universally desirable. For example, some companies (perennials) are intended to last, while other companies (annuals) are created to exploit a temporary market advantage, and could be expected to dwindle or be dismantled when circumstances change (Firnberg 1996). But within the organisational survival perspective, some have also noted that from the organisational point of view, the well-being of the individuals in the organisation can be important. "[C]reating and sustaining a distinctive competitive 
advantage can only be driven by people; by releasing and stimulating their skills, imagination and initiative, and by retaining their expertise and loyalty" (Firnberg 1996:122). The perspective is thus that people's well-being is important because it benefits the organisation.

We do not see the sustained existence of an organisation as an end in itself. Organisations are here for instrumental reasons: the production and distribution of wanted goods or services (e.g. companies in market economies); legal requirements (e.g. public schools); personal or artistic expression (e.g. a string quartet); charity (e.g. The Red Cross), etc. There are companies, governmental organisations and non-profit or civil society organisations that falter and cease to exist, while others spring into existence. Sometimes, the closing of an organisation is because it was mismanaged, but at other times, the closing organisation had little reason to continue existing. The people in the organisations usually continue with their lives, and the relevant tasks performed by the organisation are fulfilled by other organisations. Such closing and starting of organisations, and accompanying changes in the employment of individuals, are part of the creative destruction (Schumpeter 1942) that enables a society to adapt to changing conditions and to develop and adopt more appropriate and efficient ideas, processes and concepts. However, this does not exclude situations where individuals connect to, or even identify themselves with, an organisation to the effect that problems in the organisation reaches deep into their wellbeing. (Docherty, Kira \& Shani 2009).

Thus, organisations may come and go, but people working in organisations need sustainability in the sense that they should not be consumed or extinguished, burned out. We disapprove of the internal combustion organisation, the organisation that creates output by consuming and using up the people working in it, even though the business press and business consultants of the day seem to call for it by regarding workers as expendable and replaceable input resources, relentlessly chasing and eliminating organisational slack, habitually countering reported decreases in quarterly earnings by personnel cutbacks, and by terming the employees "human capital" (Westelius 2000). Organisational forms that devour people or cripple them are not part of what we view as sustainable. As an individual, you can leave an organisation. This may be sound and fruitful. But you should not be forced to leave an organisation because it destroys or damages you. Sustainability, in our sense, is a question of care and partnership - a partnership between people in the organisation and between people and the organisation. This partnership rests on mutual care: that people care about and for each other, that people care about the organisational impact of their actions and that the organisation is designed and operated in a way that displays care for the people in and around the organisation.

In other words, we are not looking for organisations that are just endurable, in the sense that they sustain over time but at great human costs. Thus, a sustainable organisation, as we want to view it, is one that can exist and operate well for an extended period of time without doing so at the expense of 
the people in the organisation; the functioning of the organisation is instrumental to the well-being of the people in the organisation, not the other way round. It is helpful that a substantial body of research confirms that for instance leadership characterised by fairness and justice also improves organisational efficiency (van Knippenberg, De Cremer \& van Knippenberg 2007), but we prefer to see the wellbeing of people as an end in itself, rather than as a means.

A definition of "organisations" may be appropriate here. Typically, dictionaries would present definitions like "a body of persons organized for some specific purpose" (Webster's 1979). Such bodies can be large or small, for profit or not for profit, limited companies, associations, congregations, foundations, etc. They can be, but need not be, legal entities. Likewise, Herbert Simon, in his by now classical Administrative Behavior, uses "organisation" to refer to "the pattern of communication and relations among a group of human beings [ ] This pattern provides to organization members much of the information and many of the assumptions, goals, an attitudes that enter into their decisions, and provide a set of stable and comprehensible expectations as to what the other members of the group are doing and how they will react to what one says and does." (Simon 1947/1997:18-19). In line with this, by organisations we mean more or less sustainable systems of cooperation between, say, three or more human beings. Such a system of cooperation needs to have goals or purposes that unite its members, which implies, for instance, that large conglomerates will be regarded as a collection of several organisations in this context. At the other end of the spectrum, small legal entities working closely together for an extended period of time can be regarded as one organisation in the sense of this article. Much of what we say will be most highly applicable to the collection of individuals who interact for an extended period of time on a daily basis, but to some degree it may also be applicable to more distant relationships, like that between the international Group manager and employees in a local office in a company.

Why, then, and when do organisations need to be sustainable? There are many reasons. In principle, an organisation needs a balance in the exchange of resources (Rhenman \& Stymne 1965; Freeman 1984; Pfeffer \& Salancik 1978). The output needs to exceed, or at least equal, the input. The formal structure under which this exchange takes place can be changed by the stroke of a pen. However, turning ideas into action requires the hands and minds of people, and changes involving people take time. Therefore, an organisation needs to be in existence for an extended period of time to provide the opportunity for people to find their place and role, and cooperate at a level of proficiency that makes the organisation a worthwhile venture. Also, in a globalised world with growing demands for equal treatment across gender and cultural borders, overcoming prejudices and cultural conflicts takes time. In addition to such reasons, related to organisational instrumentality, we identify four types of reasons for organisational sustainability - from a humanistic point of view - which will be used later to build a model of organisational design and analysis: 
Being social creatures, we need relations with other people to stay healthy and productive (Maffesoli 1996). Building relationships with others and developing the trust needed for cooperation (Axelrod 1984) or to be fellow humans to each other requires time (Selznick 1992).

- $\quad$ Learning the job takes time, especially since it builds on feedback from often complex systems of dependencies (Westelius \& Askenäs 2004). Efficiency in the job increases with practice. The newcomer is not as productive as the colleagues who have had time to learn their job, and to cooperate with the others, thoroughly. This was, for example, forcefully demonstrated by the failures of the $\mathrm{BPR}^{1}$ movement in the mid 1990s, and its obsession with speed, but also recognised, for example, in the "hundred days of grace" extended to new managers.

- In organised cooperation, we lead or are led, we make rules and adhere to rules, but only if we find them reasonable. We follow orders, but only if they fall within our zone of acceptance (Simon 1947/1997). It takes time to develop sufficient trust in the competency of a leader to make you willing to accept the leader's decisions. For the leader, it takes time to learn what the subordinates can accomplish and what the limits are for directing them (Mintzberg 1973). It also takes time to develop sound rules and routines that guide repetitive choices, and to develop the conviction that the rules are worth following.

- To continue to devote our efforts and our ingenuity to the accomplishment of the goals of the organisational cooperation, we need to see a meaning in what we do - that our efforts contribute to the achievement of something we see as worthwhile (Brown 1997; Hackman \& Oldham 1980). In this sense, the long-term effects of our work are not instantaneously visible. Only in the longer run will we be able to see whether or not we achieve the higher goals. It also takes time to move from a novice understanding of the work as a set of distinct tasks to a systems view of how the tasks s/he performs interact with each other (Sandberg 2000; Westelius \& Askenäs 2004) and with those performed by others to accomplish the organisation's ultimate goals. Before $\mathrm{s} /$ he has developed this deeper understanding, it is difficult to see whether the tasks s/he performs actually contribute to the overarching goals or not.

\section{Alternative theoretical perspectives on organisations}

The literature on organisation theory - including some of the field's "classics", as we have exemplified above and will continue to show below - is abundant with approaches focusing one aspect or other of organisational life. Whereas many writers suggest a certain perspective as the most important, others maintain that the ability to understand and switch between perspectives is more

\footnotetext{
${ }^{1}$ Business Process Reengineering
} 
useful. A widely used textbook promoting that stance, summarises some of the existing theories under four headings: Symbolic theories, Political theories, Human Resource theories and Rational Systems theories (Bolman \& Deal 1984). Since all these theory perspectives focus on important aspects, the case is made in the book that using more than one of them may provide valuable insights and may improve decision-making. We now present these four headings and relate them to the four basic concepts of our own model: Meaning, Authority, Rationality and Care - MARC

The symbolic theories aim at the deeper meaning in seemingly obvious events in organisations. Formal structures or what people say or do are treated as symbols in need of interpretation (Weick 1979). We are encouraged to search for an alternative meaning underneath the surface. For instance, these theories focus on the limits of rational planning and formal power. They tend to highlight the unexpected benefits that may develop out of disobedience in organisations. Symbolic theories suggest that managers should make intelligent use of images in order to create a sense of mission and order in the organisation. In our model, MARC, such intense search for a sense of mission most closely corresponds to the concept Meaning. Meaning stands for our need to experience what we do in the organisation as morally or existentially meaningful, in accordance with basic assumptions about what is good in life (cf. Kiefer \& Senge 1982). It includes acknowledgement of intuition and other forms of non-verbalised and non-rationalised sense-perceptions and insights as valid bases for that judgement (Barnard 1938). Emotionally driven decisions and actions - doing something because it feels right, or refraining from doing it because it feels wrong - are seen as acceptable or even commendable (Meyerson 2000).

Political theories emphasise how power is distributed, executed and negotiated in organisations (Bacharach \& Lawler 1980; Pfeffer 1981). They may use "the jungle" as an organisational metaphor and advice managers to focus their attention on how coalitions of power develop, on negotiation strategies and on conflict resolution. In MARC, this is related to the concept Authority. Authority "legal" or "traditional" in Weber's sense (Weber, 1978) stands for our need for clarified and authorised ordering of power. In a sustainably healthy organisation, power is clarified and distributed in a way that secures coordination and reduces dysfunctional power struggles. Appropriate rules and routines ("bureaucratic administration", Weber 1978) are in place and are followed by the organisational members. Those who exercise authority over others do so competently and their decisions are respected and adhered to by the others ("authority of leadership" in Barnard's parlance: Barnard 1938). You could also say that Authority, or Good Authority, deals with empowerment, providing guidelines when and where needed while not interfering unnecessarily.

Rational systems theories focus on technological systems and on knowledge production and reproduction (Churchman 1968). They propose systematic planning and design of organisational 
structures as the best way of securing the technical/economical efficiency of the organisation. Rational and explicit logic is regarded as essential. Demonstrated sound reasoning is viewed as a legitimate basis for changing and improving decisions and actions. This is close to the concept Rationality in MARC. Rationality stands for our need to understand what we are doing, why we do it (Barnard 1938; Weick 1995), and how we may utilize new knowledge and experiences in order to question and improve the way we do it (Argyris 1993).

The fourth group, Human Resource theories, focuses on the interconnectedness between individuals' social needs and capacities, and organisational design. Attention is directed at how to create a better fit between individual and organisational features, and at improving the social relations through which this can be done (Mayo 1933/2003, McGregor 1960/1987). In MARC, this is related to the concept Care. Care summarises our longing to be seen and respected as we are (cf. Buber 1923/1996), the importance we place on establishing and maintaining relationships with others that we care about (Noddings 1984/2003; Gilligan 1977) and on showing and receiving compassion and care (Noddings 1984/2003), not just trust and respect (Keifer \& Senge 1982). ${ }^{2}$ There is a relation between our concept Care and the ethics of care tradition promoted by Gilligan (1977), Noddings (1984/2003) and others. In that tradition, as in our model, care and relationships are seen as fundamental traits in human nature. However, like Meyerson (2000), we are here primarily discussing care in an organisational context, and then not only in care organisations. Also, like Meyerson, we view care and emotionally authentic connections as an important part of organisational life, not restricted to a specific gender or organisational role. This is consonant with both Gilligan and Noddings. Gilligan (1977; 1982; 1986) and Noddings (1984/2003) are careful to state that, although they both identified an ideal of care by investigating women's experience, this ideal is not female as opposed to male.

A debate in the ethics of care literature has concerned the power relation between the one-caring and the cared-for, with both a risk that the one-caring fulfils a need for caring more than actually respecting the cared-for, and a risk of perpetuating socially dominated caring roles by upholding unconditional provision of care as an ideal (e.g. Tronto 1987; Hoagland 1990). However, in our model, we think of Care as potentially two-way. There may be times when one is primarily giver and another taker, but in a healthy organisational relationship, care is not continuously unidirectional. Also, as pointed out by Noddings (1984) and reinforced in the preface to the second edition (Noddings 2003), ethical care presumes both a serious attempt by the carer to understand the need for care from the cared-for's perspective (termed engrossment by Noddings) and some kind of reciprocation

\footnotetext{
${ }^{2}$ Keifer \& Senge (1982:115) specifically note how the senior management's mission statement, in what they view as a highly successful company (Kollmorgen), includes humanistic considerations and business success in the same sentence: "to fulfill its responsibility to Kollmorgen shareholders and employees by creating and supporting an organization of strong and vital business divisions where a spirit of freedom, equality, mutual trust, respect, and even love prevails".
} 
acknowledging that the care was appreciated. These conditions are important if Care is going to serve as a component in a humanely sustainable organisational context.

\section{Values and sustainability}

As argued above in the section Sustainability and organisations, we seek sustainability in terms of principles for creating and maintaining human organised systems in which members can thrive sustainably. Such sustainability requires a complexity of perspectives in order to perceive, reflect and successfully act upon relevant internal and external events. This is in agreement with writers such as Bolman and Deal (1984) and Morgan (1997), who propose a number of perspectives or metaphors to switch between to increase our understanding of organisations. However, we go one step further. Switching between points of view can be fruitful when dealing with an organisational challenge, or when trying to improve organisational performance. But we argue in favour of an integrated approach, meaning that the four aspects outlined above can, and should, be included in one and the same model of sustainable organisation design. The first obvious reason is that, as described in the section Sustainability and organisations, each one of them emphasises a set of basic values, important for us as human cooperating beings. ${ }^{3}$ There is no obvious reason to exclude any of those values in a normative discussion about sustainable organisation design. A second reason has to do with the interconnectedness of these perspectives, something that will be developed in some detail below. Thirdly, perception, reflection and action are always guided by an underlying value base (Checkland \& Scholes 1990; Suchman 1995). Therefore, maintaining a multitude of human-centred values will make more aspects look relevant ("relevant" in this specific context is defined in accordance with the needs and nature of human beings) leading to a more human-friendly organisation. This is our main tenet developed in this article.

In our model, we have attempted to identify basic conditions that are needed to provide for a sound and sustainable organisation. Ongoing dynamism is an additional starting point; every organisation will, during its existence, experience internal and external stress and pressure to change. These challenges cannot, and should not, be avoided. The sustainable organisation is rather one that is able to deal with changes without creating health hazards. This does not mean that change is easy or effortless; it means that the organisation enables its members to deal with the stressful conditions, to which they are exposed, in a satisfactory way.

\footnotetext{
${ }^{3}$ Morgan (1997) proposes nine metaphors: machines, organisms, brains, cultures, political systems, psychic prisons, flux, transformation, and domination, and indicates the possibility of additional ones, such as ideology, gender, ecology, and games. However, he intends the metaphors to be used as an aid in perceiving "the competing dimensions of a situation" ( $p$ 428), and does not advocate that all conceivable metaphors should always be applied to a situation, or that any specific one of them is necessary. We, on the other hand, take aspects important to human wellbeing in an organisation as a starting point, rather than just looking for possible ways to view and analyse an organisation.
} 


\section{Individual and organisational sustainability}

A researcher who has investigated stress-coping capacity among individuals is Aaron Antonovsky, who developed the "SOC"-concept: Sense of Coherence (Antonovsky 1987). He investigated, from what is called a "salutogenic" approach (from the Latin salus = health and genesis = origin), why some people survived or managed to cope under extreme pressure: what does it take to keep ones health under unhealthy circumstances? Antonovsky found that it takes three things: the situation must be experienced as comprehensible, i.e. rational, understandable, consistent and predictable; it must be seen as manageable (under the influence of one's own power) at least to some degree; and it has to be experienced somehow as meaningful - coherent with, or leading to, the satisfaction of basic values.

Even though these concepts were originally developed to describe what the individual needs, we find them applicable also for discussing how we function in an organisational context. Of course, organisation members have to understand what they are supposed to do, both in terms of the tasks themselves, and in terms of having sufficient knowledge to carry out the tasks (cf. Antonovsky's concept: "Comprehensible"; Barnard 1938). Another obvious prerequisite is that they have the necessary resources at their disposal. This includes material resources (workspace, computers, etc), but also soft or intangible ones, such as information and support from colleagues or authority matching their responsibilities ("Manageable"). What sometimes goes missing, in the discussion about what it takes for an organisation to function well, is the question of what is viewed as meaningful. Of course, management is expected to formulate a vision for the future in which the organisation is a meaningful part. Most often this is done in an economic/strategic vocabulary, for example: "We are to be the leader in our market segment in five years!" Supposedly, everyone in the organisation is expected to embrace this vision as something meaningful (Checkland \& Scholes 1990; Weick 1995; Simons 1995). However, following Antonovsky's idea about meaningfulness, people's ability to handle difficulties is related to something beyond economic utility. They need to view the business, and the changes in it, as in line with what they hold as moral values in their lives (Hackman \& Oldham 1980; Maffesoli 1996; May, Gilson \& Harter 2004). Growing market shares, making a profit or meeting one's budget are not in themselves meaningful factors in this sense.

SOC has similarities with three of the four parts of the MARC model, foremost Rationality and Meaning, but also to some extent to Authority; "Manageable" implies a certain amount of individual power, and sets limits for how the authority of others can be exercised. What Antonovsky does is that he argues for the necessity of all three being present in order to preserve or restore health. Each one of them can be used separately to analyse the situation "from above" as it where. But in order to live in, and cope with, the situation, integration of perspectives is needed.

Another tradition based on the salutogenic perspective is resilience research, investigating competent coping in the face of risk and adversity (e.g. Sutcliffe \& Vogus 2003). This tradition explores how 
resilience can work at the level of the individual, the group and the organisation, linking these levels with each other. Developing and maintaining resilience requires quality resources (human, social, emotional and material) and mastery motivation (the will to overcome difficulties), allowing the individual to experience success and build self-efficacy. Linking self-confidence and confidence in the organisation's ability to cope with demanding situations, is central to resilience. If the individual is confident that the organisation is well equipped to deal with these situations, s/he will feel secure. This security is needed in order to dare and care to be open and attentive to what is happening. In turn, increased attentiveness supports the possibility to notice events in time to deal with them effectively. Experience of the organisation successfully dealing with challenging situations, then builds confidence for the future, and so on. In contrast, lacking trust in the organisation's ability to cope, the individual may fall back on what is called cognitive narrowing or constriction of control, thereby reducing his/her own capabilities, increasing the risk of failure, eventually entering a vicious circle (Mant 1983).

We recognise this ambition to combine the individual and the organisational level and aim to explore it further. Organisations build on the cooperation between people. The organisation then needs to provide its members with a working environment that does not endanger, but rather fosters, their ability to function. The organisation must develop trustworthiness, i.e. sound reasons for believing that its structures and processes are reliable and that they are powerful enough to deal with challenging situations. This supports mastery motivation, i.e. a sort of empowerment on the individual level. This way, Antonovsky's individual "manageability" concept is expanded into what we call good Authority by relating it to the organisational level. Authority, in the way we use it here, is an organisational - not individual - concept. Authority is needed in order to help coordinate, organise and decide in cases of non-trivial conflicts between individuals and to make tradeoffs between different goals. It clarifies responsibilities and competencies in the organisation, aiming at empowerment (Barnard 1938; Simon 1947/1997; Simons 1995).

In an organised context, individuals also need a social, caring climate in which they can, and will be willing to, cooperate with each other, purposefully and efficiently for an extended period of time (for reasons mentioned earlier). Antonovsky, with his individual focus and with his often extreme choices of empirical references (life in concentration camps, etc), is not very explicit on this. Rather, he explains what it takes to survive when love and care is absent. Here, focusing on less extreme situations, like contemporary work life, we claim that the ideas from Antonovsky's SOC-model therefore should be expanded with an additional, fourth prerequisite for basic human wellbeing: Care, properties of the organisation that support and promote our social needs when we cooperate with others, a normative human relations perspective (Keifer \& Senge 1982; Meyerson 2000). 


\section{The MARC model}

We have stated that a normative model of sustainable organisations should be inclusive and integrating. But how shall this integration be made? How are these values related to each other? We include four sets of values in our model: Meaningfulness, (Good) Authority, Rationality, and Care. Together, their initials form the name of the model: MARC. In a clinical research tradition (Schein 1991) the model has been used and refined in a number of practical business cases in which we have been involved as consultants: diagnosing cultural heterogeneity in a merger of two large hospitals; as an analytical tool presented in several management training programs in both the private and public sector; mapping organisational thinking among union members; supporting organisational development within a religious congregation, etc. Experiences from these practical tests of the model will be supplied later in this article (in the section Empirical experiences from working with MARC).

Based on both theoretical arguments, presented in this article, and these practical experiences, we are convinced that a sustainable organisation must reflect values in this four-dimensional sense.

When presenting our model, we illustrate it as depicted in Figure 1.

\section{Meaning Authority}

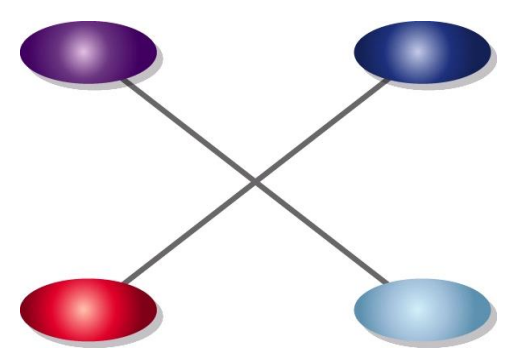

\section{Care}

\section{Rationality}

\section{Figure 1 The MARC model}

The concepts are placed in the figure according to how we view their internal relationships. ${ }^{4}$ It is possible to discern a left and a right half of the model, balancing each other. The right one, with Authority and Rationality, encompasses what is often referred to as "hard" cognitive and material resources, while the left one, with Care and Meaning, rather represents "soft", i.e. emotional and social resources.

\footnotetext{
${ }^{4}$ The graphical representation is inspired by Simons (1995), although his concepts are significantly different from ours. However, there is some degree of correspondence between our Care and his Interactive control systems, our Meaning and his Belief system, a somewhat weaker one between our Rationality and his Diagnostic control system, and an even weaker one between his Belief system and our Authority.
} 
It may also be possible to infer a balance between the upper half, building on vertical relations, on receiving and submission as basic attitudes, and the lower half, where care and rationality share horizontal dialogue as a central trait. We believe that organisations heavily leaning on the upper half easily become fundamentalist. The members are driven by a higher goal, co-ordinated by a strong and clear authority, but because of a lack of rational and/or caring dialogue, it becomes easy to turn a blind eye to the worries and questions individual people harbour. Strong goal focus and leadership also risks leaving calls for reviews and redirection unheard.

In a business where the main focus is on social, friendly relationship between the individuals and the rational aspects - the lower half of the model - a strong, common direction may be lacking. It is likely that we would find much laughter and discussion, but little coordinated action - a talkative group lacking a common voice and without much action.

The model is drawn with two diagonals, the relationship between Care and Authority on the one hand and the one between Meaning and Rationality on the other. The balance between Care and Authority is central to how leadership is performed. It is easy to see that a strong and singular emphasis on clear and tangible wielding of authority, well-defined rules, norms and obedience are insufficient to create a well-functioning business. Without Care, without seeing and accepting the particularities of the individuals involved, Authority becomes ruthless and frightening. At its worst, it can take on a pathological and single-minded focus on concrete results, evermore contrived rationalisations to legitimate the exercise of power, and an indifference to how it affects others.

But the reverse is not functioning either. There is a risk in a totally unbalanced focus on Care: the comfort trap. In it, no one wants to be the manager, no one wants to face conflicts. The relationships in the group become far more important than the organisational goals. The organisation will be characterised by this lack of leadership, which can create as much frustration as poor leadership. What is uncomfortable from a relational perspective is suppressed and left unattended. Therefore, a Care too blind and undemanding needs to be balanced by good Authority. Authority without Care is frightening. Care without Authority is unproductive.

The other diagonal, the one between Meaning and Rationality, also has something important to say about how organisations should be constituted. Both Meaning and Rationality are important starting points for a discussion of the significance of meaningful work. The concept Meaning is intended to encompass the feeling of connection of one's work with a worthwhile goal or context. Each individual should ideally experience that his/her work contributes to something good, not only for him-/herself but also for others. In order to be proud of one's work, the basic goals and tasks of the organisation need to be consonant with one's basic values. Sometimes, vision and mission statements are 
formulated in an attempt to capture such more fundamental meaning, sometimes not. What, then, characterises a good balance? On the one hand, Rationality without a purpose easily ends up in endless discussions about meaningless details. On the other hand, an exclusive focus on the ultimate Meaning of the organisation, without an interest in planning its activities in an efficient and rational way, creates an esoteric organisation aloof from reality. A short and distinct formulation of a proper balance could be: "Focus on the assignment, and have an open dialogue." To focus on the assignment includes looking beyond the immediate tasks at hand, and reflecting on what the fundamental aim of the organisation is. The open dialogue is a prerequisite for finding efficient and effective ways of fulfilling this aim. An open dialogue allows questioning and learning (Schön 1983). It is necessary to allow the business to change and adapt. It is also a requirement, if people are to understand the entirety of what is done.

\section{Balancing values}

Working with models always implies simplification. Whether we speak about governing "perspectives", "interests", "schools of thought", "theories" or "paradigms", there is always an evaluation being made reflecting basic values, i.e. conceptions about what is of value in life. Symbolic theories seem to appreciate emotions, moral intuitions and fantasy. Political theories emphasise empowerment, stability and coordination. Rational systems theories value learning, intellectual understanding and efficiency. Human Resource theories emphasise security, self-actualisation, friendship and love. All these theories reflect non-controversial conceptions of what is of value in life. In that sense, they can also be regarded as guardians of basic values in any undertaking that aims at designing sustainable organisations - especially from a humanistic point of view. It is easy to understand why we perish if these values are ignored, and there is no reason for excluding any of them in a discussion about sustainable work systems.

On the other hand, every concrete situation demands that we set priorities on our values, since all values cannot be realised at the same time. Actions imply choices, often difficult ones. In our view, it is important to remember and clarify the nature of this mixing of values that has to take place when organisation design is discussed. It is not a question of reaching a mixture of values once and for all. Rather, it is a question of arranging the context in which action takes place so that none of these values will dominate completely or be compromised, twisted or forgotten. Focus has to be on the balancing of values as these values are expressed in actions. Creating a sustainable organisation means setting the stage for a constant re-creation of this balance, and the MARC model is designed to help people achieve this. 


\section{The dynamism between the concepts}

Because we view sustainability as resulting from traits of the organising process rather than as static characteristics of an organisational structure, we need to reflect on how the four aspects in our model influence each other dynamically. By stating that they should be in balance, we declare the belief that a systematic lack of one of the aspects would lead to a less well-functioning organisation. However, as we touched upon earlier, balance does not imply that for example the leadership and its quality would stay invariant - it will, and probably should, change as time passes and conditions change. (This was pointed out already by Mintzberg in 1973.)

The dynamism between the four corners of the MARC-model can create both positive and negative loops. A lack of clear leadership ("low" A) creates poor coordination, feelings of powerlessness and thereby inefficiency and poor understanding of work processes and how they interconnect ("low" R). This creates both a feeling of futility (there is no point in doing things that lead nowhere) and irritation and poor understanding of other people's work, leading to a lack of care and respect ("low" C). We recognise this partly as a lack of "mastery motivation" with its accompanying vicious circle hinted at earlier.

Too strictly delineated work tasks and an information policy that gives little sense of interrelations and context ("low" R) make it difficult to understand why decisions go the way they do, and run the risk of making the leadership appear unsystematic and incompetent ("low" A). I feel neither seen as the one I am, nor for what I do, and this creates fear ("low" C).

A socially poor work environment lacking respect and care makes the co-workers retire into themselves and the organisation grow silent ("low" C). Rationality then decreases since the critical examination and dialogue no longer works ("low" R). The shared goal recedes, replaced by everyone's attempts to protect themselves and their tasks ("low" M). When the open discussion disappears, so does the possibility for well-founded decisions, and the lack of openness erodes the trust in colleagues and management alike ("low" A). They all appear to have hidden agendas.

In different ways, the process may end up with a situation where the organisation's members' experience of the organisation eats away at trust, and they begin to expect dysfunctional behaviour from their surroundings. In the end, the organisation is "low" in all four dimensions and can even turn harmful - TIFF rather than MARC, see Figure 2.

Instead of good and comprehensible authority that the members can embrace, directions and decisions seem vicious and arbitrary (Tyranny). The exercise of logic, questioning and search for improvements 
has been replaced by Ignorance. The care extended to and from others has disappeared, as Fear has gained hold of people. And the feeling of meaning has eroded, leaving in its wake a sense of Futility.

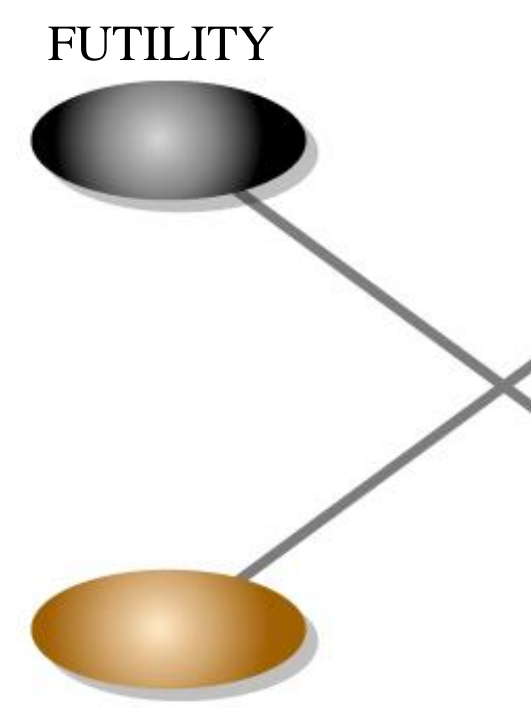

FEAR

\section{Figure 2 The TIFF model}

How can TIFF be avoided? The obvious suggestion is to continuously nurture the good aspects of MARC. But what if the organisation has already slipped that far? In a state where social trust has eroded, and the views on tasks and overall aim lead to constant conflict, how can you start to improve the situation? It depends, of course, but we do not believe that attending to each corner in turn would work. As long as the quotidian work is brimming with inefficiency, accompanied by the irritation caused by poor routines or lack of decisions and coordination, the ability to attend to the soft side of processes will not materialise. Who can find the motivation to work with the team spirit or the corporate creed when you cannot even get the operational reports out of the printer? On the other hand, it will not be possible to successfully deal with the "hard" issues until you have re-established a trustful and open dialogue. Who wants to discuss distribution of power with people of whom they are afraid?

The members of the organisation need to establish trust in their ability to successfully deal with issues, by systematically working with all four aspects. Building trust takes far longer than erasing it. Lying once is sufficient to convince everyone that I am not telling the truth, but how many times do I then have to be truthful until everyone is convinced that I no longer lie? Positive spirals are thus less clear than negative ones. 


\section{Threats to sustainability and how to cope with them}

Contemporary working life has certain features that pose a threat to a good balance in our terms. Both external and internal issues may arise that threaten the good functioning, and thus the survival, of the organisation.

At a general level, fragmentation of world-views - or maybe better "the age of authenticity", as Taylor (2007) calls it - has had profound effects on the possibility to form sustainable identities, at least in the Western world. Value-changes in society and growing individualism may pose a threat to the social construction of Meaning that underlies the feelings of identity and purpose in life, feelings so important for a well-functioning organisation. Internationalisation implies that old and wellestablished norm and value systems are being challenged by "new" ones. In practice, it can mean a change in ownership that brings new cultural elements into the organisation, or more global operations that bring employees in face-to-face contact with alternative religious or moral systems. In those situations, the management of the organisation has to establish a manner of reaching some kind of consensus around what it is that needs to be sustained in the organisation, what it is that is of real value. Fundamentalist tendencies of all kinds - maybe as a reaction to what we just described - pose further contemporary threats to organisations' ability to maintain Meaning. They tend to distance the organisation from its environment, cutting off rational criticism and thus alternative but meaningful ideas. The solution, naturally, is to open up for external influences, something that takes trust and time.

A good Authority system will be threatened by sub-optimisation, i.e. when sub-parts of the system act in order to maximise their own survival without considering systemic or long-term effects. This might happen, for instance, if "profit centres" or "internal competition" is introduced without taking account of the needs of the whole organisation. Sub-optimisation may of course also occur as a result of individualism in the form of career development plans, and feedback- and bonus-systems, promoting a kind of unenlightened self-interest. Some forms of "value-based management" have manipulative tendencies, threatening in terms of sustainability from a humanistic point of view (Brytting \& Trollestad 2000). Also, advanced bureaucratic or technical systems may be developed on a selfsustained level that permits them to "act" more or less autonomously, disconnected from reality. Under circumstances like these, sustainability requires the (re-)establishment of decision-making processes, or a kind of "solidarity system" that urges, or even forces, individuals and sub-systems to act in the common interest of the organisation. To make these systems function and to re-establish a sound authority system takes trust and time.

Information technology may improve conditions for rational decision-making, but sustainability in the long run will always have to deal with fundamental uncertainty. This is a real dilemma for the 
rationalistic mind that expects every question to have a right answer. Students of shifting societal value systems have shown that this kind of "secular" rationality is gaining ground at the expense of traditional inherited norms (Ingelhart 1990). Rationality can then run berserk when never-ending floods of information roll in at the same time as expert opinions differ. Insisting on rationality in those situations will paralyse the organisation. Sustainable organisations realise that, and handle large amounts of information through open dialogues without losing sight of Meaning, thereby securing quality and relevance. Sometimes they also execute Authority in order to break deadlocks. Meaningful dialogues and finding out people's "zone of acceptance" takes trust and time.

Even the value we call Care can be perverted. Egoism, as a by-product of individualistic tendencies in society, is one threat. But so is a too exclusive focus from the management's side on individual wellbeing. It can become paternalistic and also create an atmosphere in which real conflicts are suppressed and not openly confronted - the "comfort trap". Care must also respect the integrity of individuals, something that may be at risk if too much pressure is put on worker involvement, commitment and development of shared organisational values. Once again, the solution is an open, respectful dialogue. From another perspective, Care becomes problematic as relations between people tend to become more and more abstract and anonymous. Instead of meeting our fellow human beings eye-to-eye, they have become voices on the phone, signatures in an e-mail or numbers arranged in rows and columns. It may then take some intellectual and empathical effort to act responsibly, since our moral intuitions may not even realise that our actions have consequences for people of flesh and blood. Setting this straight takes trust and time.

The Swedish theologian Lennart Nordenfelt has defined health as 'the ability of an individual to realise that which is of value in life for that individual' (Nordenfelt 1991). Thus, one could say that this article is an attempt to point out the direction in which not only organisational sustainability, but also organisational health, can be realised. Sustainable work systems realise that which is of value for human beings. This expression has - intentionally - a double meaning. Sustainability requires both insights into the basic needs interacting human beings have, and the capacity to satisfy them. Trust and time could interact to make this possible. Radical and repeated organisational change, in combination with a single-minded focus on cutting organisational "slack", are therefore the two most dangerous enemies of sustainability.

\section{Empirical experiences from working with MARC}

So far, the validity of the model rests on logical reasoning grounded in organisational and salutogenic research, and on it appearing useful to our clients and members in organisations where we have employed it. Over the past seven years, we have also tested the generative capacity (Cooperrider 1986; Gergen 1978) of the MARC model. We have used the model in 24 organisations and in seminars 
organised by another eleven organisations, where the seminars have been aimed at the organisations' partners or to people regardless of organisational affiliation. The organisation-specific applications have been both in the public and non-profit sectors. The seminars have included both public- and private-sector participants.

One class of our clients' reasons for using the model has been to deal with specific problems, projects or challenges in an organisation:

- In four cases, managers or management teams have brought us in to help deal with problems in getting different individuals and different professions to share one view of the organisation, of common goals and values, and in prioritising work for the common good, rather than just for the individual or profession-based goals and values

- In two organisations, health-related organisational development projects were carried out, where the project managers brought us in to help include organisational parameters, rather than just exercise, food and smoking, in the project

- In another two organisations undergoing problematic changes, HR managers saw the model as a source of support and inspiration for handling the current challenges during transition.

Another class of reasons is general competence development, to increase the capability for dealing with future challenges, rather than to address a currently pressing need:

- In three organisations, the HR department conducts recurring seminars to develop managers' competence and provide them with shared language and models

- In two partnership organisations, we were brought in as part of the specific competence development seminars these organisations offer to their partners

- At two universities, MARC seminars have been part of executive education programs

- Six conference or seminar organisers looking for interesting and thought-provoking models have brought us in to conduct MARC workshops.

The third class of reasons is to structure a specific analysis: 
- In one organisation, we restructured and modified the employee satisfaction questionnaire to make it more balanced in MARC terms

- In a gender equality investigation, the MARC model was used as the basis for a survey to investigate values concerning organisation and career.

We will return to an example from each of these three classes, but first, we present some general observations from the use of the model. In the first two classes of applications, the number of participants has ranged from ten to 400 . The generality of the model provides considerable interpretive viability (Benders \& van Veen 2001), thus allowing a tailoring of it to appear relevant to the individual organisation. Ahead of presenting the model in an organisation, we typically review policy documents to identify quotations that illustrate the model's concepts. This mirror of the official self-image is used to discuss the balance. Is any corner very strongly emphasised? Is any corner conspicuously absent, and what may that mean? That it is not allowed to talk about it, or that it is so unproblematic that it is deemed unnecessary to mention? For example, in a small academic institution, where top management wanted to promote a sense and practice of shared mission and cooperation, Care was absent in the official statements. An interpretation of this was that the highly professional staff shared a strong sense of importance of the general subject area ("high" M), but worked alone, each in their specialised area and did not really view each other as partners in a work group. Authority worked in a bilateral fashion on an individual, not a collective basis, and rationality and questioning was highly regarded and vigorously upheld. The image of the official documents thus accurately described the present situation in the organisation, rather than the state that top management wanted to achieve. Noting this imbalance was a first step on the path towards increased commonality.

In the merger of two large, professional organisations with strong rational, evidence-based ideals, we were brought in to help develop a way of making company culture a topic for discussion and consideration. In seminars with the top 100 managers, we had them describe their own unit and the corresponding unit in the other organisation in MARC terms. At the start, a large portion of the managers denied that there were culture differences or that culture was an issue that could cause friction if not attended to. At the end of the seminars, many of them had come to realise (or acknowledge) that there were indeed differences, and that the shared language of MARC helped them discuss, identify and start to resolve potential problematic differences. We were then asked to train the HR department, who continued to spread the MARC concept to 450 managers at the next level.

In workshops, the participants use the model to make self-assessments of the part of the organisation that is relevant to them, and discuss their assessment with others. One topic is how similar or dissimilar the assessments are, and why. This can for example help reveal that the self-image in one 
department does not correspond with how people in other parts of the organisation view that department. That insight can in turn start a change in self-image or a dialogue that increases the mutual understanding between close and more distant colleagues. Another topic is to come up with suggestions on how to improve aspects of the model that they view as lacking in their organisation. How can we, concretely, start improving Care - tomorrow and in the longer run? A question that often arises is what part of the organisation to analyse. The question indicates that people tend to perceive the characteristics of different parts of the organisation differently. For example, Care is more prevalent in ones proximity, and Authority tends to be experienced as less transparent and reasonable the greater the distance to the manager or rule-setter.

The reaction from the participants is typically that the model makes sense to them and that the underlying balancing ideas are important. All corners have at one point or other appeared as the most underdeveloped according to participant assessments, and we have yet to meet someone who claims to work in a perfectly balanced organisation. Also, the perceived balance tends to differ depending on type of organisation and function within the organisation. However, it is not obvious that the external focus of the organisation corresponds to competent acting inside. For example, in a parish striving to care for its parishioners, employees can experience considerable lack of Care, and Meaning is by no means unproblematic and shared. In a government agency creating and enforcing rules, Authority may be experienced as the aspect most in need of improvement.

\section{Balancing the educational institution}

Our first example is from an education institution dealing with performing art. This is a small organisation with roughly 20 employees - almost all of them being the only specialists in their respective field in the organisation. Most of them were also strongly convinced about the meaningfulness of their work. Having the opportunity to develop young talented people into a career in the highest form of art - their art form - made them feel motivated and proud. The small size of the organisation meant that few of them had colleagues with the same expertise: voice treatment, directing, scenography, costumes, etc. When we were asked to work with this organisation, it had recently had a controversial shift in management, strongly resented by much of the staff, but supported by the board. A managerial culture based on personal artistic track-records and charismatic personality was now replaced by a new dean without a personal career on stage and with an organisational as well as artistic focus. The new dean felt a need for better administrative structures and expected the employees to deliver as a unit and not only as individual experts. The dean also saw the whole art form

as changing in the future: experimental performances, use of technology, more free-lance than permanent employment, etc. 
Presenting MARC in this situation meant that the employees acquired a set of concepts with which they could start to analyse the organisational design of their institution and not only their personal and highly emotional relations. Using the model, they could discuss the dysfunctional processes that could threaten the quality of their work and poison the organisational climate. Special focus was put on the Care - Authority diagonal and on the importance of trust in order to make any kind of partnership at work possible.

One year after our first appearance we where asked to come back for a recapitulation of the model and for guiding them in a pro-active discussion about common development needs. The attention paid to the Care - Authority diagonal during the year had resulted in a sense of partnership that allowed them to develop a shared sense of meaning and formulate a strategy. The discussion this time focussed on putting the strategy into concrete action in such a way as to achieve genuine participation as partners in moving the school into the future.

\section{Establishing a fruitful employer - labour-union dialogue}

Our second example is The Central Government Social Partners' Council (Partsrådet), a non-profit association whose members are The Swedish Agency for Government Employers (SAGE), and its social dialogue counterparts; OFR (Public Employees' Negotiation Council/S,P,O as well as the labour unions Saco-S and SEKO). In 2006 these organisations signed a formal partnership agreement with the intent of supporting change and renewal work in governmental workplaces. Today Partsrådet has, as one of its responsibilities, to realise the intentions behind this partnership agreement, to breathe some new life into it, especially into the local partnership agreements that have been signed at most government agencies. The challenge was to present a constructive alternative to the formal Swedish codetermination law which regulates the decision-making processes at every workplace in the country. At the time of our intervention, this codetermination procedure was deemed to be unfit to regulate day-to-day workings, sometimes even exaggerating conflicting interests between the different parties. Partsrådet then decided on using MARC as a tool for discussing organisational and cultural fundamentals - like trust, power, mandate, dialogue, loyalty, obedience, documentation, vision etc and relating these concepts to an organisational reality in MARC terms. The goal was to support practical partnership at work.

We conducted a series of eight one-day conferences over a three-year period. At each occasion some 40 people from seven or eight governmental agencies participated, forming a total of about 300 participants from well over 50 agencies. Participants represented both labour unions and employers.

MARC was used to sort out participants' present experiences from cooperation. Why is cooperation so difficult? What made it sometimes possible? Sorting these good and bad experiences into the MARC 
model conveyed to the participants an insight into the difference between sustainable partnership, and negotiation and conflict resolution. They returned with the insight that setting up meetings and writing documents will not matter until the basic questions have been sorted out: What are we doing here? What is our mandate? Why should I have faith in the process? What can I do to improve my own trustworthiness?

The importance given by the participants to Meaning, and loyalty towards the agency's mission, was impossible to ignore. The importance of implementing a good Authority - e.g. clear and wellcommunicated mandates as well as loyalty towards formal structures, rules and decision - was also verified by the participants. The need for Rationality was discussed at length. Special attention was given to the possible dilemma between being loyal towards one's own area of expertise (Rationality) and loyalty towards formal decisions (Authority). Care was agreed to be absolutely fundamental for any type of constructive dialogue. When looking for examples of unbalanced organisations, we were able to come up with all kinds of imbalances except a "Care"-less organisation still in continued operation.

MARC was also used to outline the specific characteristics of a well-functioning partnership committee, especially what kind of difficulties may appear in such a group if unbalanced in terms of the model's aspects - lack of sense of meaning (M), unclear mandates (A), lack of learning and follow-up (R), and unsolved personal conflicts (C).

At one of the conferences, there was considerable tension between those who held that partnership meetings must start by building trust through undirected, unstructured dialogue, and those who maintained that the primary concern was to develop the formal structure in terms of meeting agendas, rules for how to record differing opinions in connection with decisions, etc. By framing these apparent opposites as aspects of Care and Authority along the leadership diagonal, the participants could suddenly see that it was not a question of either or, and that one opinion had to win over the other. The new framing made it apparent that a bit of structure could be necessary for some to feel comfortable to engage in dialogue, while the building of trust would be necessary to fruitfully cooperate on developing a structure. Thus, the mutual dependence and complementarity became apparent, rather than the differences, and this helped the group overcome the deadlock and start to move forward.

\section{Exploring gender differences in working-life values}

Our third example is a major survey performed by the labour union The Swedish Confederation of Professional Associations $(\mathrm{SACO})^{5}$. We translated the four aspects of the model into 50 questions

\footnotetext{
${ }^{5}$ In Sweden, membership in labour unions is common, and neither a political statement nor something that in other ways could be expected to lead to biases in comparison with the working population in general.
} 
which were distributed to SACO members ( $>1.000$ responses and $>50 \%$ response rate). The basic idea was to test the hypothesis that value-based attitudes concerning organisation and career differ between men and women ${ }^{6}$ and between superiors and subordinates. If that is so, gender-specific organisational conceptions might explain why women may choose not to enter into hierarchical careers. Also, it is sometimes argued that because of men's traditional power position, any difference between men's and women's perceptions of these issues would work against gender equality because female-specific expectations would challenge the "homosocial" (Lipman-Blumen 1976) status quo, something that would be reinforced by labelling alternative conceptions as female (Tronto 1987). However, no statistically significant differences were found - neither between men and women nor between superiors and subordinates (Krafft 2007). This indicates that the MARC concepts are general rather than gender- or hierarchy-specific. The results also contradict the often stated notion that men emphasise "hard" aspects (A and R) while women emphasise "soft" ones (M and C).

It is interesting to note that the top of the list of importance contains a mix of items from different categories - (Rationality, Authority and Care) (see Table 1). The Meaning item "how important is it to you that the basic aims of the organisation is in line with your own values" also scored high for both men and women. Thus, a balance between the MARC aspects, rather than predominance for one of them, appears to be generally important.

\begin{tabular}{|l|l|r|r|}
\hline $\begin{array}{l}\text { Rank for } \\
\text { women }\end{array}$ & $\begin{array}{l}\text { Question } \\
\text { How important is it to you ... }\end{array}$ & $\begin{array}{r}\text { Mean for women (1-5: } \\
\text { 1=unimportant, } \\
\text { 5=absolutely necessary) }\end{array}$ & $\begin{array}{r}\text { Mean and rank } \\
\text { for men }\end{array}$ \\
\hline 1 & $\begin{array}{l}\text { to have a meaningful life outside of } \\
\text { work? }\end{array}$ & 4.58 & $4.34(1)$ \\
\hline 2 & $\begin{array}{l}\text { that new knowledge is retrieved and } \\
\text { used at work? (R) }\end{array}$ & 4.08 & $3.78(3)$ \\
\hline 3 & $\begin{array}{l}\text { that there are clear and realistic } \\
\text { goals? (A) }\end{array}$ & 4.03 & $3.75(4)$ \\
\hline 4 & $\begin{array}{l}\text { that you can show care for others at } \\
\text { work? (C) }\end{array}$ & 4.00 & $3.80(2)$ \\
\hline 5 & $\begin{array}{l}\text { that your workgroup has fun at } \\
\text { work? (C) }\end{array}$ & 3.94 & $3.73(5)$ \\
\hline 6 & $\begin{array}{l}\text { to understand why you perform tasks } \\
\text { the way you do? (R) }\end{array}$ & & 4.03 \\
\hline
\end{tabular}

Table 1 Top-ranking items for men and women

Both men and women prefer to find their meaning in life in their private as opposed to their professional lives. No statistically significant differences are found between genders or managerial positions. However, when forced to choose, higher managers (both men and women) would tend to be

\footnotetext{
${ }^{6}$ For example, Gilligan $(1977 ; 1982 ; 1986)$ found that men and women tend to hold different values and follow different moral development paths. If so, it could also be expected that values regarding organisations and work could differ.
} 
more willing to prioritise work ahead of their private life than lower-level managers and non-managers (see Figure 3). This shift appears already at the middle-management level for men. Note that the shift is not drastic; a majority at all levels would still prioritise their private lives ahead of work.

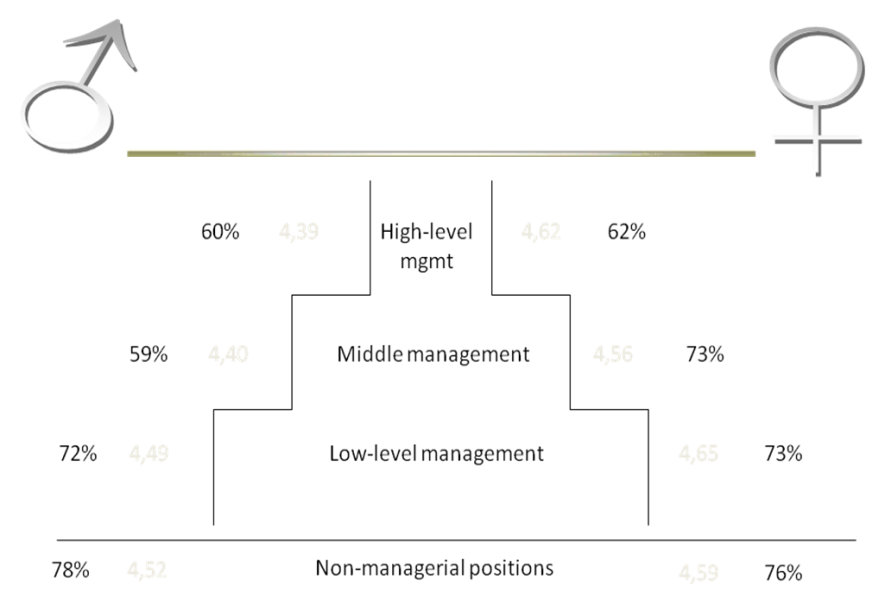

Figure 3 work-life balance. Percentage who would prioritise private life ahead of work. Mean score for importance of meaningful life outside of work.

One interesting tendency in the data - although not statistically significant - suggests that men and women during a hierarchical career tend to become more similar in their organisational expectations, but coming from different starting positions. Men with low power - i.e. lacking subordinates - have a slightly "smaller" profile ${ }^{7}$ in MARC terms than women with low power. Moving up the hierarchy, men increase their profile and women reduce theirs. One could interpret this as a kind of learning experience. Men have smaller but, if they climb the career ladder, growing expectations as to what life in the organisation might mean to them. Women start with larger expectations but become more realistic (?) when they reach power.

The general lack of statistically significant differences between men and women and between hierarchical levels regarding values in organisational life in this investigation is thought-provoking. However, we cannot claim that it would be generally and globally valid. The studied population consists of Swedes with an academic degree. It can be expected that studying at university shapes people and decreases differences. With $33 \%$ of the adult population having tertiary education, Sweden is a fairly highly educated nation, although by no means at the top of the list (OECD 2011:38). It can also be argued that Sweden in a global comparison is a seemingly equal society, with less pronounced power distance, gender differences and income differences (UNDP 2011:135) than many others. Still, from a Swedish point of view, the results have not only surprised us, but also attracted considerable attention when presented at seminars held by SACO.

\footnotetext{
${ }^{7}$ Smaller in the sense of a lower rating on all four aspects.
} 


\section{Conclusions and future research}

As we have demonstrated above, support for the importance of each of the four aspects Meaning, Authority, Rationality and Care as perspectives in analysing and understanding organisations can be found in the organisational research literature. Our contribution is to argue the case that they represent four important human needs that need to be attended to in balance in an organisation if cooperation between the individuals in the organisation is to be sustainable from a human-centred perspective. MARC is designed to help visualise and focus this balance. When using the MARC model to structure analyses and facilitate discussions in organisations that have sought our aid, all four aspects have at one point or other been a major source of imbalance.

The MARC model has considerable interpretive viability. In no organisation have we been met by "this is not relevant to us". Each individual and organisation can load MARC with concretisations that are important and relevant to them. And when we have used it to structure an employee satisfaction questionnaire or to explore gender differences we have been able to detail it according to instantiations of Meaning, Authority, Rationality and Care that are relevant in those contexts.

The applications of the model have demonstrated its generative capacity. The task of exploring the model has inspired practice-based discussions that have filled the model with locally relevant cases and examples and led to concrete and specific ideas for improving local workplace practice from a human-centred perspective. The graphical representation helps emphasise important connections between aspects: the diagonals balancing Authority with Care (the leadership diagonal) and Rationality with Meaning (the operations diagonal); the "soft" left side with the "hard" right side; and the vertical relations of the top half with the dialogues of the bottom half. As Benders and van Veen (2001) note, new labels can focus attention on familiar but unresolved problems and solutions. New labels might even facilitate the difficult but important need of balancing "espoused theory" with "theory-in-use" (Argyris \& Schön 1978) as a way of improving learning in organisations. Perceived relevance is an important starting point. From that starting point, the underlying idea of balance and the relationships between different parts of the model provide means for taking the analysis and dialogue beyond that which is already known and agreed upon. Mutual care and partnership are central in these discussions, but do not just centre on the Care dimension of the model, but also on search for Meaning, increased emphasis on Rationality or exercise of and adherence to Authority.

The model is thus a framework for situated discussions, departing from the specific organisation and its context. It can aid in developing good governance systems, but does not prescribe any specific solutions. The model is human-centred, based on fundamental human needs. Financial gain is not an end in itself, and is thus not a core concept in the model - unlike in many management models. However, there is nothing that prevents the use of the model in a for-profit organisation where it is 
deemed important to not compromise important human values. We believe that such concern is morally desirable, but acknowledge that it is not a prerequisite for economically profitable operation. As long as there is a large labour market and the organisation is not held responsible for how its employees fare, the internal combustion organisation is an economically, though not morally, viable alternative.

Returning to the concepts care and partnership, we see care as individual and non-instrumental. Showing care does not require that the subject - be it a person, another living thing, an object or a system such as the environment - deserves care. Care does not require reciprocity, although it often gives rise to it. Partnership, on the other hand, carries an expectation of mutuality, and is thus somewhat more instrumental. However, it is not an agent-theoretical concept. It does not rest on distrust and tit-for-tat arrangements for keeping contracts. Partnership is typically intended as longterm, and is based on an expectation that both parties see an enduring common future as well as remember and appreciate the common history. Partnership builds on expectations that the parties will act to solve problems that arise. In an organisational context, this requires a basis of professional trust, a faith in that each party will be able to deliver, rather than just a liking for the other party. Upholding partnership will to a large extent depend on the bottom half of the MARC model - an open dialogue and some degree of mutual care; partnership is not a-personal, it will tend to include some degree of liking. It will also need to build on some degree of shared sense of Meaning. Furthermore, the mutuality of authority is a form of partnership - accepting to be led and taking responsibility for leading.

Living in a Western society and drawing on Western research and ideals, we cannot claim that the MARC model would be globally valid, although we are not aware of any major limitations in applying it to other cultural traditions. However, we have only applied it in Swedish settings. It would therefore be interesting to test if it holds up to application in other cultural settings.

Another potential line of future research would be to study if our intellectual and experience-based perceptions concerning the importance of MARC-balance to sustainability hold up to systematic process study. Longitudinal case research could for example seek to establish to what extent increased MARC balance increases the well-being of the individuals in the studied organisations. Furthermore, we have so far come across a number of organisations in different settings where perceived problems have been analysed and addressed with the help of the model. As the model builds on human needs, a potential implication is that imbalances are detrimental to the well-being of individuals in the organisation. This could be could be studied by analysing organisations that have not sought help, in order to determine if they exhibit considerable imbalances without noticeable detrimental effects for the individuals in the organisations. 


\section{References}

Antonovsky, A (1987) Unraveling the mystery of health - how people manage stress and stay well. San Francisco, Jossey-Bass.

Argyris, C (1993) Knowledge for action: a guide to overcoming barriers to organizational change.

San Francisco, Jossey-Bass.

Argyris, C and Schön D A (1978) Organizational learning - a theory of action perspective. Reading, Addison-Wesley.

Axelrod, R (1984) The evolution of cooperation. New York, Basic Books.

Barnard, C (1938) The functions of the executive. Cambridge, MA, Harvard University Press.

Bacharach, A B and Lawler, E J (1980) Power and politics in organizations. San Francisco, JosseyBass.

Benders, J and van Veen, K (2001) What's in a fashion? interpretative viability and management fashions. Organization, 8(1), pp 33-53.

Bolman, L and Deal, T (1984) Modern approaches to understanding and managing organizations.

San Francisco, Jossey-Bass.

Brytting, T and Trollestad, C (2000) Managerial thinking on value-based management. International Journal of Value-Based Management, 13(1), pp 55-77.

Brown, A D (1997) Narcissism, identity and legitimacy. Academy of Management Review, 22(3), pp 643-686.

Buber, M (1923/1996) I and Thou. New York, Touchstone.

Checkland, P and Scholes, J (1990) Soft systems methodology in practice. Chichester, England, John Wiley.

Churchman, C W (1968) The systems approach. New York, Delacorte Press.

Coase, R H (1937) The nature of the firm. Economica, N. S. 4(16), pp 386-405.

Cooperrider, D L (1986) Appreciative inquiry: toward a methodology for understanding and enhancing organzational innovation. PhD. Case Western Reserve University, Dept. of Organizational Behavior.

Docherty, P; Kira, M and Shani, A B (eds) (2009) Creating sustainable work systems: developing social sustainability. London, Routledge.

Firnberg, D (1996) Creating the sustainable enterprise - staying competitive and staying alive: the 1995 annual conference of the Strategic Planning Society. Long Range Planning, 29, pp 121-122.

Freeman, R E (1984) Strategic management - a stakeholder approach. Boston, Pitman.

Gergen, K J (1978) Toward Generative Theory. Journal of Personality and Social Psychology, 36, pp 1344-1360.

Gilligan, C (1977) In a different voice: women's conceptions of self and of morality. Harvard Educational Review, 47, pp 481-517.

Gilligan, C (1982) In a different voice. Cambridge, MA, Harvard University Press. 
Gilligan, C (1986) Reply by Carol Gilligan. Signs, 11(2), pp 324-333.

Hackman, R and Oldham, G (1980) Work redesign. Reading, MA, Addison Wesley.

Hoagland, S L (1990) Some concerns about Nel Noddings' caring. Hypatia, 5(1), pp 109-114.

Inglehart, R (1990) Culture shift in advanced industrial society. New Jersey, Princeton University Press.

Kiefer, C F and Senge, P M (1982) Metanoic organizations in the transition to a sustainable society. Technological Forecasting and Social Change, 22, pp 109-122.

Kjellberg, A and Werneman, A (2000) Business innovation - innovative teams, competence brokers and beehive structures - in a sustainable work organisation. CIRP Annals - Manufacturing Technology, 49(1), pp 355-358.

Krafft, C (2007) Mer lika än olika - kvinnliga och manliga akademiker om organisationsvärderingar och karriär. (in Swedish. More similar than different - female and male academics on values concerning organisation and career). Stockholm, SACO.

van Knippenberg, D; De Cremer, D and van Knippenberg, B (2007) Leadership and fairness: the state of the art. European Journal of Work and Organizational Psychology, 16, pp 113-140.

Lipman-Blumen, J (1976) Toward a homosocial theory of sex roles: an explanation of the sex segregation of social institutions. Signs, 1(3), pp 15-31.

Lozano, R (2008) Envisioning sustainability three-dimensionally. Journal of Cleaner Production, 16, pp 1838-1846.

Maffesoli, M (1996) The time of the tribes. London, Sage.

Mant, A (1983) Leaders we deserve. Oxford, Martin Robertson \& Company.

May, D R; Gilson, R L \& Harter, L M (2004). The psychological conditions of meaningfulness, safety and availability and the engagement of the human spirit at work. Journal of Occupational \& Organizational Psychology, 77(1), pp 11-37.

Mayo, E (1933/2003) The human problems of an industrial civilization: early sociology of management and organizations. London, Routledge.

McGregor, D (1960/1987) The human side of enterprise. London, Penguin.

Meyerson D E (2000) If emotions were honoured: a cultural analysis. In: S Fineman (ed) Emotion in organizations. London, Sage, pp 167-183.

Mintzberg, H (1973) The nature of managerial work. New York, Harper \& Row.

Morgan, G (1997) Images of organization. Thousand Oaks, Sage.

Noddings, N (1984/2003) Caring: a feminine approach to ethics and moral education. Berkeley: University of California Press.

Nordenfelt, L (1991) Livskvalitet och hälsa. (in Swedish. Quality of life and health) Linköping, Almqvist \& Wiksell.

OECD (2011) Education at a glance 2011: OECD indicators. OECD Publishing. http://dx.doi.org/10.1787/eag-2011-en 
Pfeffer, J (1981) Power in organizations. Marshfield, Pitman.

Rhenman, E and Stymne, B (1965) Företagsledning i en föränderlig värld. (in Swedish. Management in a changing world). Stockholm, Aldus/Bonniers.

Pfeffer, J and Salancik, G R (1978) The external control of organzations - a resource dependence perspective. New York, Harper \& Row.

Sandberg, J (2000) Understanding human competence at work: an interpretative approach. The Academy of Management Journal, 43(1), pp 9 - 26.

Schein, E H (1991) Legitimating clinical research in the study of organisational culture. WP\# 328891-BPS. Cambridge, MA, MIT Sloan School of Management.

Schön, D (1983) The reflective practitioner - how professionals think in action. New York, Basic Books.

Schumpeter, J (1942) Capitalism, socialism and democracy. New York, Harper \& Row.

Selznick, P (1992) The moral commonwealth - social theory and the promise of community. Berkeley, University of California Press.

Simon, H A (1947/1997) Administrative behavior. 4th ed. New York, The Free Press.

Simons, R (1995) Levers of control: how managers use innovative control systems to drive strategic renewal. Boston, Harvard Business School Press.

Suchman, L (1995) Making work visible. Communications of the ACM, 38(9), pp 56-64.

Sutcliffe, K M and Vogus, T J (2003) Organizing for resilience. In: K S Cameron, J E Dutton and R E Quinn (eds) Positive organizational scholarship. San Francisco, Berrett-Koehler Publishers.

Taylor, C (2007) A secular age. Cambridge, MA, The Belknap Press of Harvard University Press.

Tronto, J C (1987) Beyond gender difference to a theory of care. Signs, 12(4), pp 644-663.

UNDP (2011) Human development report 2011. Basingstoke, Hampshire, Palgrave Macmillan.

Weber, M (1978) Economy and society: an outline of interpretive sociology. G Roth and C Wittich (eds). Berkeley, University of California Press.

Webster's new twentieth century dictionary (1979) $2^{\text {nd }}$ ed. New York, Simon and Schuster.

Weick, K (1979) The social psychology of organizing. New York, McGraw-Hill.

Weick, K (1995) Sensemaking in organizations. Thousand Oaks, Sage.

Westelius, A (2000) Virtuell kontakt och kunskapsspridning - mot ökad demokrati? (in Swedish. Virtual contact and knowledge dissemination - towards increased democracy?). Report 2000:112. Göteborg, Stiftelsen IMIT.

Westelius, A and Askenäs, L (2004) Getting to know your job - a social actor perspective on using information technology. Information Technology Journal, 3(3), pp 227-239.

Williamson, O E (1975) Markets and hierarchies: analysis and antitrust implications. New York, The Free Press. 


\section{FIGURES}

Figure 1: The MARC model

\section{Meaning \\ Authority}

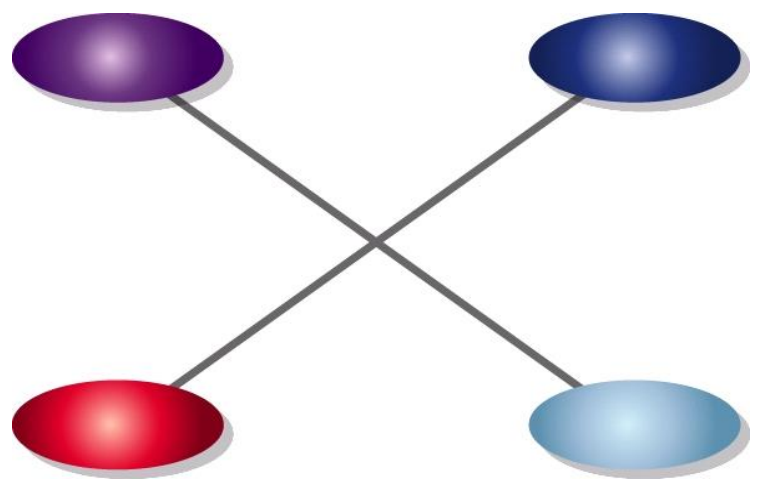

Care

Rationality 
Figure 2: The TIFF model

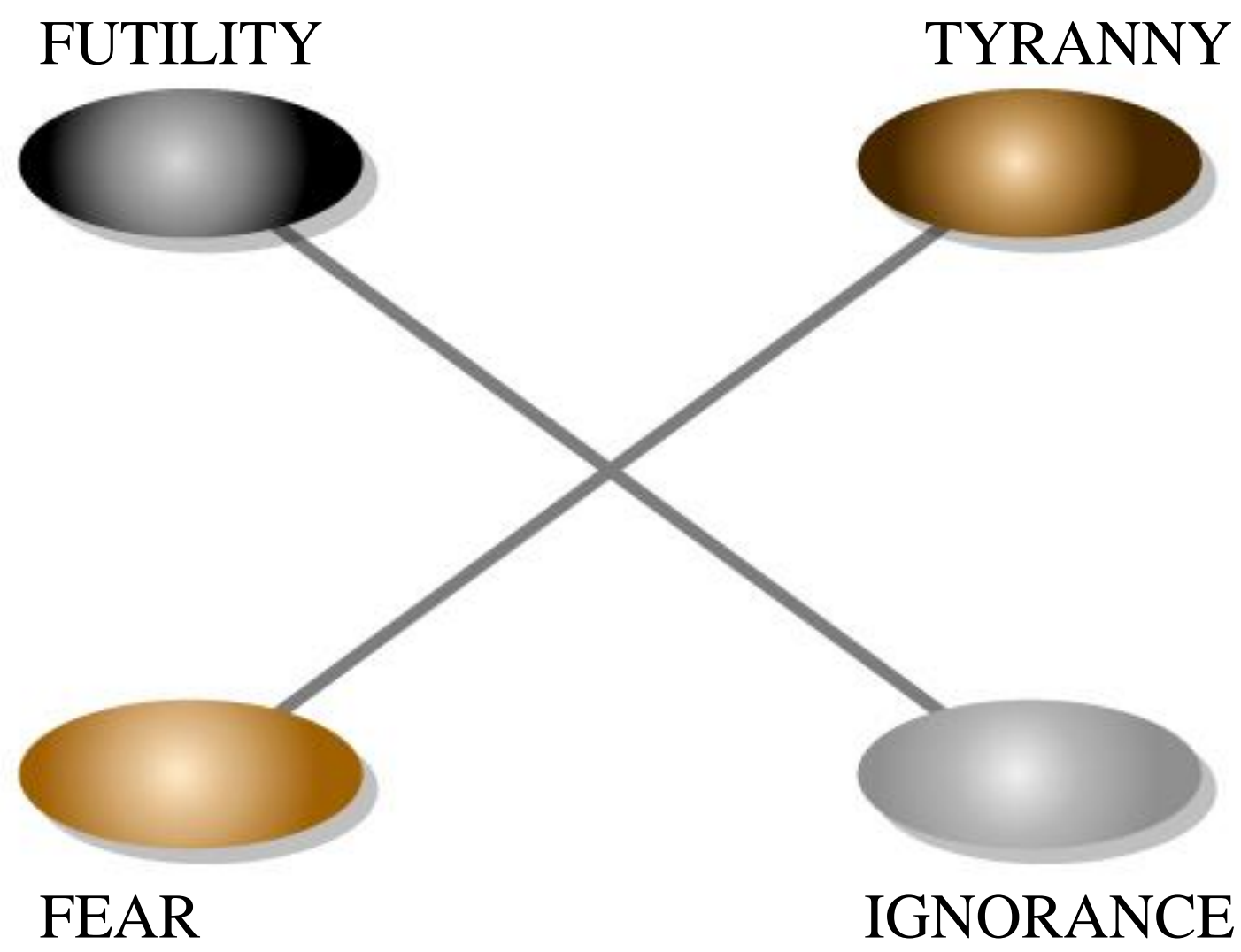


Figure 3: work-life balance. Percentage who would prioritise private life ahead of work. Mean score for importance of meaningful life outside of work.

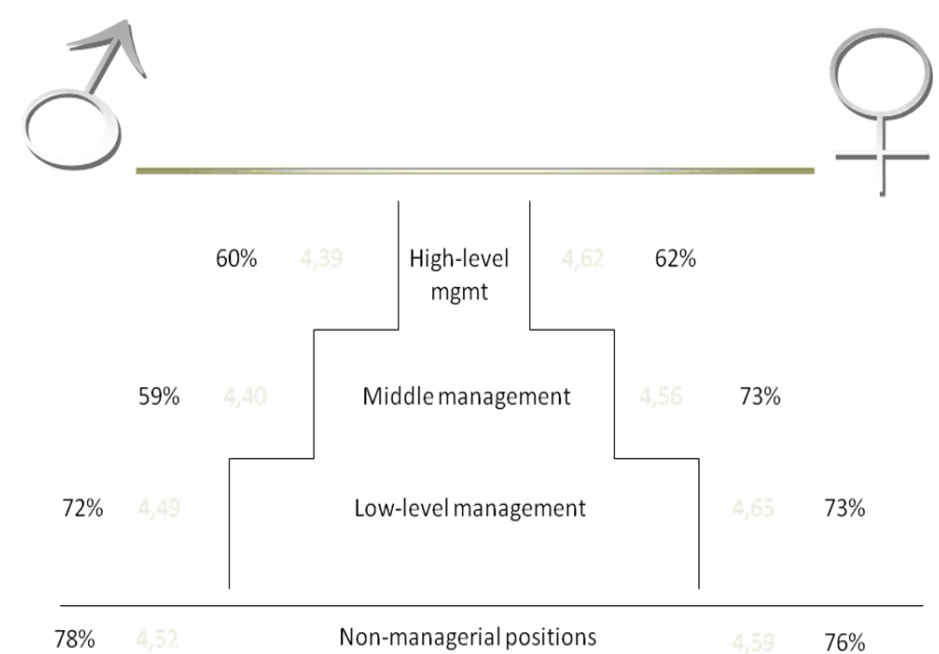

